$1-1-2014$

\title{
Quantification of Free Sialic Acid in Human Plasma through a Robust Quinoxalinone Derivatization and LC-MS/MS Using Isotope-labeled Standard Calibration
}

\author{
Dan Wang \\ Cleveland State University \\ Xiang Zhou \\ Cleveland State University \\ Lin Wang \\ China Medical University \\ Sihe Wang \\ Cleveland Clinic \\ Xue-Long Sun \\ Cleveland State University, x.sun55@csuohio.edu \\ Follow this and additional works at: https://engagedscholarship.csuohio.edu/scichem_facpub \\ Part of the Analytical Chemistry Commons, and the Biochemistry Commons \\ How does access to this work benefit you? Let us know! \\ Publisher's Statement \\ https://doi.org/10.1016/j.jchromb.2013.11.016
}

\section{Recommended Citation}

Wang, D.; Zhou, X.; Wang, L.; Wang, S.; Sun, X. Quantification of free sialic acid in human plasma through a robust quinoxalinone derivatization and LC-MS/MS using isotope-labeled standard calibration. Journal of Chromatography B 2014, 944, 75-81.

This Article is brought to you for free and open access by the Chemistry Department at EngagedScholarship@CSU. It has been accepted for inclusion in Chemistry Faculty Publications by an authorized administrator of EngagedScholarship@CSU. For more information, please contact library.es@csuohio.edu. 


\title{
Sialyltransferase inhibition and recent advances is
}

\author{
Libo Wang ${ }^{\mathrm{a}, *}$, Ying Liu ${ }^{\mathrm{a}}$, Lijun $\mathrm{Wu}^{\mathrm{a}}$, Xue-Long Sun ${ }^{\mathrm{b}, *}$ \\ a College of Pharmacy, Harbin Medical University, Baojian Road 157, Nangang District, Harbin 150081, PR China

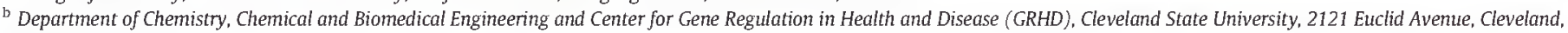 \\ OH 44115, United States
}

\section{A R T I C L E I N N F O}

Article history:

Received 3 March 2015

Received in revised form 31 May 2015

Accepted 8 July 2015

Available online 18 July 2015

Keywords:

Sialic acids

Sialylation

Sialyltransferases

Polysialyltransferases

CMP-sialic acid

Fluorinated sialic acid

\begin{abstract}
A B S T R A C T
Sialic acids, existing as terminal sugars of glycoconjugates, play important roles in various physiological and pathological processes, such as cell-cell adhesion, immune defense, tumor cell metastasis, and inflammation. Sialyltransferases (STs) catalyze the transfer of sialic acid residues to non-reducing oligosaccharide chains of proteins and lipids, using cytidine monophosphate $\mathrm{N}$-acetylneuraminic acid (CMP-Neu5Ac) as the donor. Elevated sialyltransferase activity leads to overexpression of cell surface sialic acids and contributes to many disease developments, such as cancer and inflammation. Therefore, sialyltransferases are considered as potential drug targets for disease treatment. Inhibitors of sialyltransferases thus are of medicinal interest, especially for the cancer therapy. In addition, sialyltransferase inhibitors are useful tool to study sialyltransferase function and related mechanisms. This review highlights recent development of inhibitors of sialyltransferases reported since 2004. The inhibitors are summarized as eight groups: 1) sialic acid analogs, 2) CMP-sialic acid analogs, 3) cytidine analogs, 4) oligosaccharide derivatives, 5) aromatic compounds, 6) flavonoids, 7) lithocholic acid analogs, and 8) others. This article is part of a Special Issue entitled: Physiological Enzymology and Protein Functions.
\end{abstract}

\section{Introduction}

Sialic acids (SAs), a family of 9-carbon containing acidic monosaccharides, often terminate the glycan structures of cell surface and secreted glycoconjugates such as glycoproteins and glycolipids. They are found on both $\mathrm{N}$ - and $\mathrm{O}$-linked glycans, being attached to either galactose (Gal) and $N$-acetylgalactosamine (GalNAc) units via $\alpha 2,3$ - or $\alpha 2,6$-linkages, or to SA via $\alpha 2,8$ - or $\alpha 2,9$-linkages, whose syntheses are catalyzed by specific enzymes (Fig. 1) [1]. In addition, various substituents present on carbon 4-, 5-, 7-, 8- and 9-positions generating more than 50 SA species. Their $\mathrm{C}-2$ quaternary carbon center with one carboxylate group and two oxygen substitutions makes them unique from other common sugars. The C-5-amino derivative represents the well-known neuraminic acid, and its amino functional group can be either acetylated ( $N$-acetylneuraminic acid, Neu5Ac) or glycolylated ( $N$-glycolylneuraminic acid Neu5Gc). KDN (3-deoxy-D-glycero-Dgalacto-non-2-ulopyranosonic acid), a sialic acid without amino functionality at $\mathrm{C}-5$ position, is also found in human beings. The most abundant sialic acid is Neu5Ac.

Given their terminal location on glycans and their hydrophilic and electronegative features, sialic acids ( $\mathrm{N}$-acetylneuraminic acid) play very important roles in regulating cellular interactions with ligands, microbes and neighboring cells and in controlling cellular activation, dif- ferentiation, transformation and migration [2,3]. The levels and linkages of sialic acids named as sialylation status vary upon cell activation related to both physiological and pathological processes [4]. Changes in sialylation of cell surface modulate cellular activity as well [5]. Therefore, cell surface sialic acids are considered as very important molecules in regulating many physiologically and pathologically important processes.

In eukaryotic cells, Neu5Ac is synthesized in the cytosol and then is transferred to nucleus and activated by cytosine 5 -monophosphate $\mathrm{N}$-acetylneuraminic acid (CMP-Neu5Ac) synthetase to form CMPNeu5Ac that then goes to Golgi to be transferred to glycoconjugates by sialyltransferases, which are subsequently secreted or delivered to cell surface (Fig. 2). So far, twenty sialyltransferases have been identified for catalyzing the addition of sialic acids to terminal non-reducing position of the oligosaccharides of different sugar acceptors in different linkages on proteins and lipids (Table 1) [5-7]. Sialyltransferases normally locate at the Golgi apparatus as integral membrane proteins adding sialic acids to glycoconjugates during their syntheses. In addition, some sialyltransferases are also expressed as soluble enzymes [8] and sialyltransferases activity at plasma membrane are also reported in immune cells [9]. Each sialyltransferase presents high selectivity toward its acceptor substrate and create $\alpha 2,3-, \alpha 2,6-$, and $\alpha 2,8$-linkages, respectively. Sialyltransferases can be organized in four families depending on their linkage specificities and acceptor substrates: (i) the ST3Gal family, catalyzing the addition of sialic acid to a terminal galactose of $\mathrm{N}-, \mathrm{O}$-linked glycans and glycolipids in $\alpha 2,3$-linkage; (ii) the ST6Gal family, adding $\alpha 2,6$-linking sialic acid to galactose residues of $\mathrm{N}$-glycans; (iii) the ST6GalNAc family, adding sialic acid to terminal 


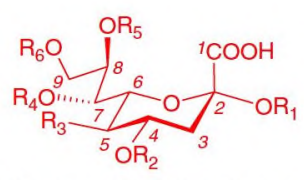

$\mathrm{R}_{1}=\mathrm{OH}$ in free $\mathrm{SA}$; alpha linkage to $\mathrm{Gal}(3 / 6)$ GalNAc (3/6), or Sia $(8 / 9)$

$\mathrm{R}_{2}=\mathrm{H}$, or $\mathrm{Ac}$

$\mathrm{R}_{3}=\mathrm{NHAc}(\mathrm{Neu} 5 \mathrm{Ac}), \mathrm{NHGc}$ (Neu5Gc), OH (KND)

$\mathrm{R}_{4}=\mathrm{H}$, or $\mathrm{AC}$

$\mathrm{R}_{5}=\mathrm{H}$, or $\mathrm{Ac}$

$R_{5}=H$, or $A c$
$R_{6}=H$, or $A c$

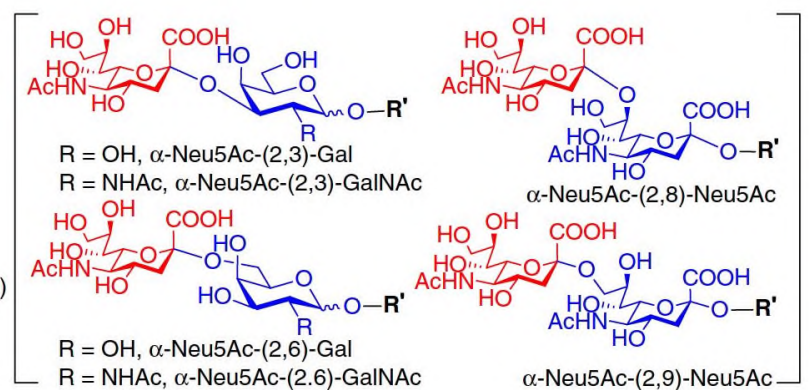

$\alpha-N e u 5 A c-(2,9)-N e u 5 A c-$

Fig. 1. Structures of sialic acids (SAs) and their natural linkages.

$\mathrm{N}$-acetylgalactosamine (GalNAc) residues of glycoproteins and glycolipids, in $\alpha 2,6$-linkage; and finally, (iv) the ST8Sia family, the only known sialyltransferases promoting the linkage to another sialic acid residue in $\mathrm{N}$ - or $\mathrm{O}$-glycans, in $\alpha 2,8$-linkage (Table 1 ). Overall, the levels and linkages of sialic acids named as sialylation status are controlled by the levels and activities of sialyltransferases, which vary upon cell activation related to both physiological and pathological processes.

\section{Hypersialylation and sialyltransferase inhibition}

The level of cell surface sialic acid expression is highly related to many pathological processes. For example, cancer cells express high density of sialic acids known as hypersialylation that contributes to cancer cell progression and metastasis. The high expression of sialic acids can protect cancer cells from apoptosis, promote metastasis, and has been suggested to confer resistance to therapy [10-13]. Overexpression of sialyltransferases and other glycosyltransferases during malignant transformation and progression results in aberrant sialylation of cancer cells [14-16]. Therefore, interfering hypersialylation may provide a practical approach in cancer therapy and thus the overexpressed sialyltransferases are potential drug targets. In addition, it has been found that overexpression of polysialic acids is related to cancer progression and metastasis recently. Therefore, polysialyltransferases have been considered as an attractive anti-cancer target as well.

Sialylation donor (CMP-Neu5Ac), acceptor, and the transition state are involved in the sialic acid transfer process catalyzed by the sialyltransferases. Therefore, analogs of CMP-Neu5Ac, acceptor, and the transition state were proposed toward the development of sialyltransferase inhibitors. The early developments on sialyltransferase inhibitors were well summarized in comprehensive review papers in 2003 [17,18]. Since then, tremendous investigations have been conducted for exploring effective sialyltransferase inhibitors, especially, for anticancer agent development. In addition, novel sialyltransferase inhibitors from natural product screening showed promising results. This review highlights the inhibitors of sialyltransferase and polysialyltransferase reported since 2004 , with variety of structures and with both in vitro and in vivo activities. The inhibitors are summarized as eight groups: 1) sialic acid analogs, 2) CMP-sialic acid analogs,
3) cytidine analogs, 4) oligosaccharides derivatives, 5) aromatic compounds, 6) flavonoids, 7) lithocholic acid analogs, and 8) others.

\subsection{Sialic acid analogs}

Most glycosyl transfer reactions proceed through a flattened halfchair conformation with a substantial oxocarbenium-ion character [19]. Therefore, sugar donor analogs and transition-state analogs can be used as potent inhibitors of glycosyltransferases. Fluorinated sialic acid analog was identified as transition state inhibitor of sialyltransferases earlier [20]. However, its high hydrophilic property prevents it from efficiently crossing cell membranes and thus its potential utility in vivo. Paulson and co-workers reported peracetylated analogs of sialic acid bearing a fluorine atom proximal to the endocyclic oxygen (P-3F $\mathrm{F}_{\mathrm{ax}}$-Neu5Ac, 1, Fig. 3) as a cell-permeable specific inhibitor of the sialyltransferases $[21,22]$. This is an elegant approach by taking advantage of the relaxed substrate specificity of enzymes in the sialic acid salvage pathways and its ability to accommodate unnatural analogs of sialic acid. Their results showed that $\mathrm{P}-3 \mathrm{~F}_{\mathrm{ax}}-\mathrm{Neu} 5 \mathrm{Ac}$ was readily converted to the corresponding donor substrate analog intracellularly. This intermediate then effectively shuts down the synthesis of a spectrum of sialylated glycan epitopes and remodels the cell-surface glycome within days. Further, they confirmed that the inhibitor alone or in combination with peracetylated analogs of fucose substantially inhibits the formation of the sialylated and fucosylated tetrasaccharide sialyl Lewis X (SLe $\left.{ }^{X}\right)$ in a human myeloid cell line (HL-60 cells), abrogating its interaction with E- and P-selectins, which recruit effector cells to inflammatory sites. Most recently, they reported their further in vivo study results that $\mathrm{P}-3 \mathrm{~F}_{\mathrm{ax}}-\mathrm{Neu} \mathrm{AAc}$ acts as a global sialyltransferase inhibitor in mice and causes the kidney and liver dysfunction. Administering $\mathrm{P}-3 \mathrm{~F}_{\mathrm{ax}}$ Neu5Ac to mice dramatically decreases sialylated glycans in cells of all tissues tested, including the blood, spleen, liver, brain, lung, heart, kidney, and testes. These results confirmed a critical role for sialosides in the liver and kidney function and documented the feasibility of pharmacological inhibition of sialyltransferases for in vivo modulation of sialoside expression. These studies paved the way for using sialic acid analog inhibitors to explore the roles of sialylated glycans in biology and mechanisms of disease and opened the possibility of using sialic

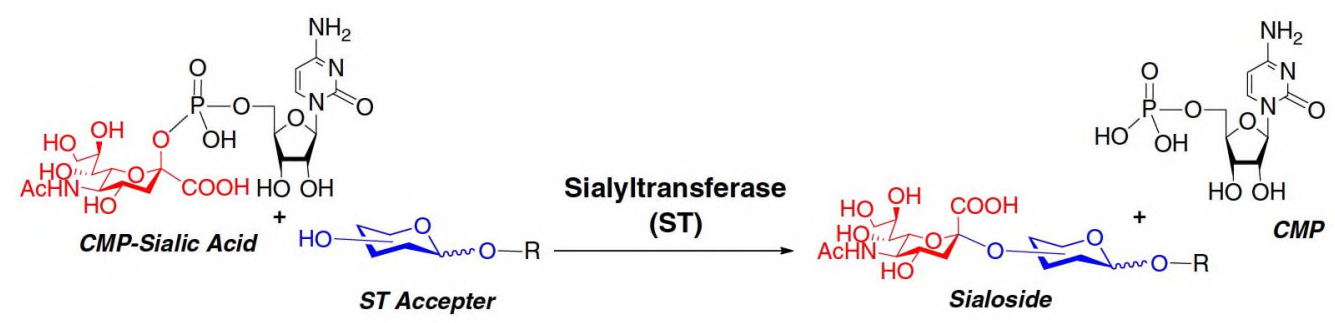

Fig. 2. Sialyltransferases catalyzed transfer of sialic acid to a suitable glycan by using CMP-sialic acid. 
Table 1

Human sialyltransferases.

Modified from Refs [5-7].

\begin{tabular}{|c|c|c|}
\hline Sialyltransferase & Preferred acceptor saccharide & Glycan specificity \\
\hline ST3Gal-I & Galß1,3GalNAC & O-glycan \\
\hline ST3Gal-ll & Gal $31,3 \mathrm{GalNAC}$ & O-glycan \\
\hline ST3Gal-III & Gal $31,3(4)$ GlcNAC & $\mathrm{O}$-glycan, $\mathrm{N}$-glycan \\
\hline ST3Gal-IV & Gal $31,4(3)$ GlcNAC & $N$-glycan, $O$-glycan \\
\hline ST3Gal-V & Gal 31,4 Glc-ceramide & Glycolipid \\
\hline ST3Gal-VI & Gal $\beta 1,4 \mathrm{GlCNAC}$ & $N$-glycan, glycolipid \\
\hline ST6Gal-I & Galß1,4GICNAC & $N$-glycan \\
\hline ST6Gal-II & Galß1,4GlcNAc & N-glycan \\
\hline ST6GalNAC-I & $\begin{array}{l}\text { Gal } \beta \text { NAc } \alpha 1, \text { O-Ser/Thr } \\
\text { Gal } \beta 1,3 \text { GalNAc } \alpha 1 \text {, O-Ser/Thr }\end{array}$ & O-glycan \\
\hline ST6GalNAc-II & Gal 31,3 GalNAc $\alpha 1$, O-Ser/Thr & O-glycans \\
\hline ST6GaINAc-Ill & Sia $\alpha 2,3 \mathrm{Gal}(31,3 \mathrm{GalNAC}$ & O-glycan \\
\hline ST6GalNAc-IV & Sia $\alpha 2,3 \mathrm{Gal}(31,3 \mathrm{GalNAC}$ & O-glycan \\
\hline ST6GalNAc-V & GM1b & Glycolipid \\
\hline ST6GalNAc-VI & All $\alpha$-series gangliosides & Glycolipid \\
\hline ST8Sia-l & Sia $\alpha 2,3 \mathrm{Ga} \mid(31,4 \mathrm{Glc}$-ceramide & Glycolipid \\
\hline ST8Sia-Il & Siac2,3Gal(31,4GlcNAC & $N$-glycan on $\mathrm{NCAM}^{\mathrm{a}}$ \\
\hline ST8Sia-Ill & Sia $2,3 \mathrm{Gal}(31,4 \mathrm{GlcNAC}$ & $N$-glycan on NCAM \\
\hline ST8Sia-IV & $(\operatorname{Sia} \alpha 2,8)_{n} \operatorname{Sia} \alpha 2,3$ Gall $31-R$ & $N$-glycan on NCAM \\
\hline ST8Sia-V & GM1b, GT1b, GD1a, GD3 & Glycolipid \\
\hline ST8Sia-Vl & $\operatorname{Sia} \alpha 2,3(6) \mathrm{Gal}$ & Sialic acid on $\mathbf{0}$-glycan \\
\hline
\end{tabular}

a NCAM: Neural cell adhesion molecule.

acid analog as drug for disease with highly expressed sialic acids and sialyltransferases.

Recently, Edma and co-workers reported the potential of $\mathrm{P}_{-}-3 \mathrm{Fax}^{-}$ Neu5Ac to block the synthesis of sialoglycans in murine melanoma cells and the consequences on cell adhesion, migration, and in vivo growth [23]. Their results showed that $\mathrm{P}-3 \mathrm{~F}_{\mathrm{ax}}-\mathrm{Neu} 5 \mathrm{Ac}$ readily causes depletion of $\alpha 2,3-/ \alpha 2,6$-linked sialic acids in B16F10 cells for several days. Even long-term inhibition of sialylation for 28 days was feasible without affecting cell viability or proliferation. Moreover, $\mathrm{P}-3 \mathrm{~F}_{\mathrm{ax}}{ }^{-}$ Neu5Ac proved to be a highly potent inhibitor of sialylation even at high concentrations of competing sialyltransferase substrates. Further, P-3F $\mathrm{F}_{\mathrm{ax}}$-Neu5Ac-treated cancer cells exhibited impaired binding to poly-L-lysine, type I collagen, and fibronectin and diminished migratory capacity. Finally, blocking sialylation of B16F10 tumor cells with this sialic acid analog reduced their growth in vivo. These results indicated that $\mathrm{P}-3 \mathrm{~F}_{\mathrm{ax}}$-Neu5Ac is a potent glycomimetic capable of inhibiting aberrant sialylation that can potentially be used for anticancer therapy. In general, sialylation is a necessary process in all cells, thus sialyltransferase inhibitors may affect physiological important sialylation as well. In order to avoid disrupting the physiologically important processes, the site specific approaches are much needed related to its therapeutic efficiency. Most recently, this group reported an enhanced pharmacokinetic approach by formulation of $\mathrm{P}-3 \mathrm{~F}_{\mathrm{ax}}$-Neu5Ac into poly(lactic-co-glycolic acid) nanoparticles coated with antityrosinase-related protein-1 antibodies for targeted delivery of P-3F $\mathrm{F}_{\mathrm{ax}}$-Neu5Ac into cancer cells [24]. They showed that an intravenous injection of melanoma-targeting P-3Fax-Neu5Ac nanoparticles prevents metastasis formation in a murine lung metastasis model. This targeting strategy to interfere with sialic aciddependent processes at the pathological sites is expected to be useful for

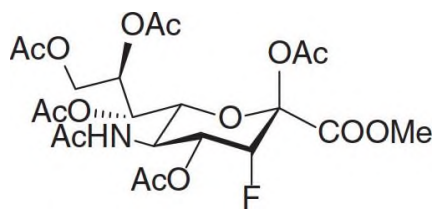

Fig. 3. Sialic acid analog inhibitor of sialyltransferases. 1, Inhibition of enzyme: $\alpha 2,3-/ \alpha 2,6-$ ST, Refs: [21-24]. cancer therapy and infection and inflammation diseases. Its further preclinical testing is anticipated.

\subsection{CMP-sialic acid analogs}

CMP-sialic acid is synthesized in the nucleus and then transported into the lumen of the Golgi apparatus via a CMP-sialic acid transporter, where sialyltransferase catalyzes the transfer of the sialic acid moiety to glycans attached to ceramides and glycoproteins (Fig. 2) [7]. Analogs of the nucleotide sugar donor substrates have been identified as potent inhibitors with selective and broad inhibition properties for glycosyltransferases. Therefore, CMP-sialic acid analogs have also been reported as potent inhibitors of sialyltransferases $[17,18]$. On the other hand, by taking both the donor's high affinity and acceptor's high selectivity, bisubstrate analogs, in which donor and acceptor analogs are covalently attached to each other, have also been proposed and confirmed as potent and selective inhibitors of sialyltransferases. Izumi et al. reported a bisubstrate analog containing the donor substrate (CMP-Neu5Ac) mimic and the acceptor substrate (galactose) and partial structure of the bisubstrate analog containing an ethylene group in place of the exocyclic anomeric oxygen of CMP-Neu5Ac (2-6) (Table 2) [25]. Among these bisubstrate analogs, cytidin-5'-yl sialylethylphosphonate (2) showed the highest inhibiting activity against rat recombinant $\alpha 2,3$ and $\alpha 2,6-\mathrm{ST}\left(\mathrm{IC}_{50}=0.047,0.34 \mathrm{mM}\right)$.

It is still unclear about the specific binding sites of sialyltransferases for the donor CMP-Neu5Ac. But the modification of Neu5Ac of CMP-Neu5Ac for seeking effective sialyltransferase inhibitors is worth exploring . Hosoguchi and co-workers reported that modification at C-5 position of CMP-Neu5Ac with bulky steroid analog (7) had strong impact to the catalytic action by sialyltransferases [26]. It showed that compound 7 is a highly promising inhibitor against $\alpha 2,3-\mathrm{ST}$ (ST3Gal III) $\left(\mathrm{IC}_{50}=8.2 \mu \mathrm{M}\right)$. Considering that many inhibitors inspired from transition-state analogs during glycosylation catalyzed by $\alpha 2,3-/ \alpha 2,6-$ STs showed much higher inhibitory effects on $\alpha 2,6$-STs rather than $\alpha 2,3$-STs [18], these results suggested that the donor binding site of $\alpha 2,6$-STs might be quite different from those of $\alpha 2,3$-STs, although both $\alpha 2,3 / \alpha 2,6$-STs share a natural CMP-Neu5Ac as a redundant donor substrate. In another study, C-5 position modified CMP-sialic acid analog carrying a fluorine atom at $\mathrm{C}-3$ of sialic acid moiety was reported by Kanie and ito [27]. The CMP-5"-fluorescently labeled 3"-F-Sia derivative (8) (Table 2 ) was accepted by CMP-sialic acid transporter and exhibited high inhibitory activity against STs $\left(K_{\mathrm{i}}=31.7 \mathrm{mM}\right)$. These two researches above suggested that modifications at $\mathrm{C}-5$ position of Neu5AC without loss of an original amide linkage and C-3 position with small fluorine allow for ideal molecular design and further optimization study of highly selective inhibitors against various sialyltransferases.

It is a concern that charged phosphate linkage in CMP-Neu5Ac may impart poor cellular permeability and is prone to phosphatase activity resulting in a significant or total loss of activity. To address whether non-charged CMP-Neu5Ac can be effective competitive inhibitors to sialyltransferase, Zou and Jennings designed a library of CMP-Neu5Ac analogs with a non-charged linkers replaced with a nonionic triazole moiety (compounds $\mathbf{9}, \mathbf{1 0}$ ) (Table 2) [28]. These mimics still contain both the sialic acid and cytidine residues responsible for binding to the sialyltransferase active site. In addition, instead of sialic acid, a 2-deoxy-2,3-dehydroacetylneuraminyl moiety was connected to cytidine by a triazole or a sulfamide linkage as CMP-Neu5Ac analogs (compounds 11-17) (Table 2). They expected that this might help to achieve trigonal planarity at the anomeric center of the transition state involved during glycosylation, while also by slightly increasing hydrophobicity. Further, compounds lack both sialic acid and a phosphodiester linkage that were replaced, respectively, by an aryl group and an isosteric sulfamide linker were designed as well (compounds 18-35) (Table 3). Their inhibition study confirmed that the first types of molecules (compounds 9, 10) are competitive inhibitors against 
Table 2

CMP-sialic acid analog inhibitors of sialyltransferases.

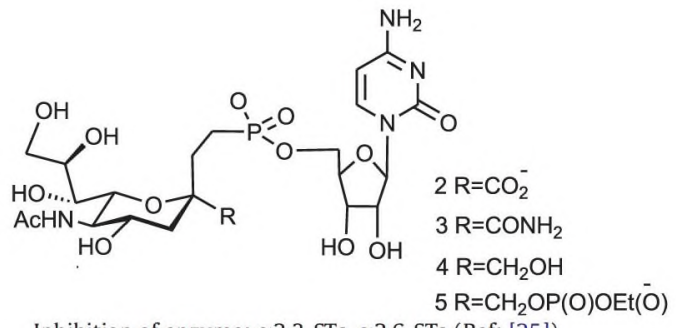

Inhibition of enzyme: $\alpha 2,3-S T s, \alpha 2,6-S T s$ (Ref: [25])

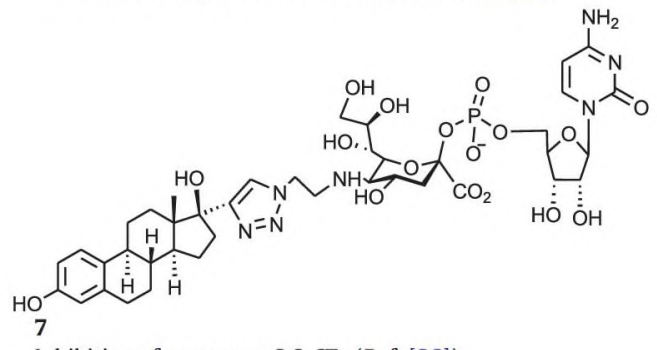

Inhibition of enzyme: $\alpha 2,3-$ STs (Ref: [26])

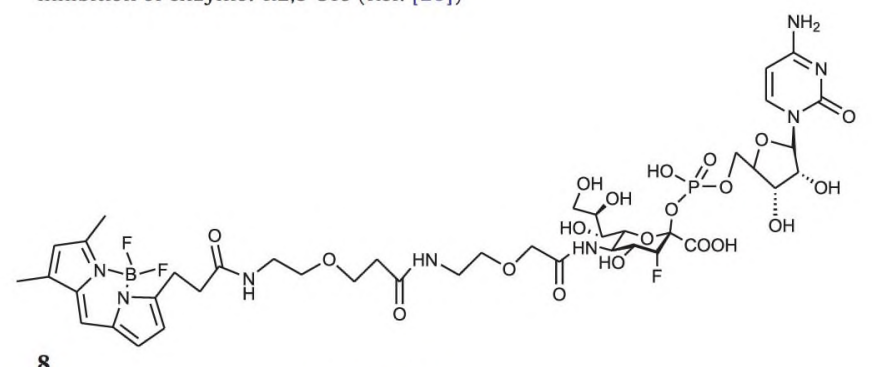

Inhibition of enzyme: $\alpha 2,3-S T$ (Ref: [27])

${ }^{\mathrm{OH}} \mathrm{OH}$

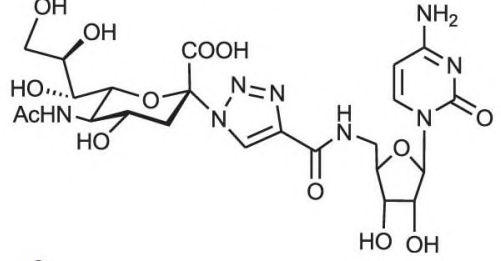

Inhibition of enzyme: $\alpha 2,6-S T s$ (Ref: [28])<smiles></smiles>

11

Inhibition of enzyme: $\alpha 2,6-S T s$ (Ref: [28])

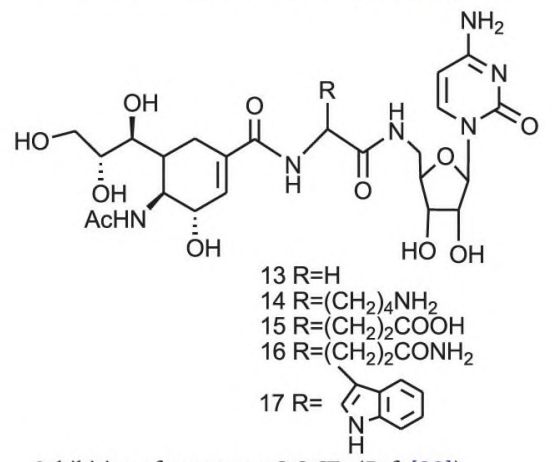

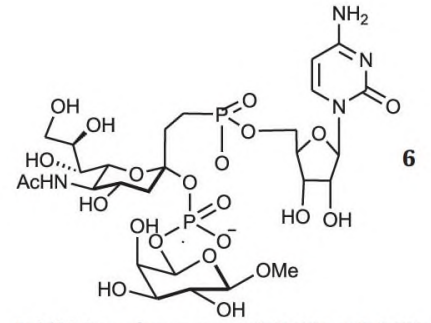

Inhibition of enzyme: $\alpha 2,3-S T s, \alpha 2,6-S T s$ (Ref: [25])

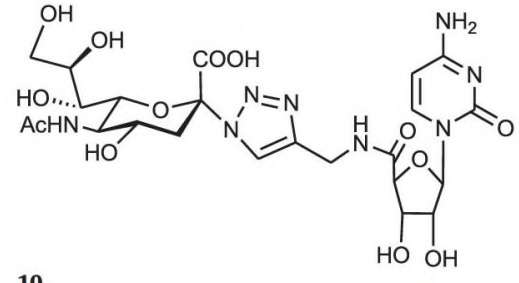

10

Inhibition of enzyme: $\alpha 2,6-S T s$ (Ref: [28])<smiles></smiles>

Inhibition of enzyme: $\alpha 2,6-S T s$ (Ref: [28]) 
cytidine conjugates against Campylobacter jejuni sialyltransferase (Cst06), whereas the last two types could only inhibit the enzyme non-competitively. These results indicated that increasing hydrophobicity of a molecule may improve its binding. As they pointed out, the better way to improve the bioavailability of a sialyltransferase inhibitor is not to eliminate the charge, but rather to temporary mask the charge and make a pro-inhibitor [28].

\subsection{Cytidine analogs}

Schmidt and co-workers proposed a transition-state model of SN1-type mechanism of sialyl transfer for designing inhibitors that exhibits particularly high binding affinities to $\alpha 2,6$-sialyltransferases [29]. They found that replacement of the neuraminyl residue by a wide range of aryl rings or hetaryl methylphosphonate residues (thiazole, benzothiazole, benzoxazole, benzothiophene and thiophene) in transition-state analogs of CMP-Neu5Ac led to readily accessible and potent inhibitors of $\alpha 2,6$ - and $\alpha 2,3$-sialyltransferases (compounds 36 47) $[29,30]$. In addition, based on the structures of cytidine and adenosines, Lenselot's group synthesized some inhibitors of STs by replacing the 5'-alcohol with triazole derivatives (compounds 48-51) [31]. They found that $5^{\prime}$-triazole adenosines were less efficient inhibitors of $\alpha 2,3$-sialyltransferase than their cytidine analogs, which suggested the hydrophobic functionality and the cytidine group are clearly required for the improved binding. Later, Satomi and co-workers synthesized several transition state mimics by applying regio- and stereospecific rearrangement initiated by monohydrolysis of a symmetric diester (compounds 52-57 in Table 3) [32]. However, there is no sialyltransferases inhibiting activity reported yet.

Polysialic acid is a homopolymer of $\alpha 2,8$-linked sialic acid attached to the neural cell adhesion molecule (NCAM) and plays an essential role in neuronal development [33]. Its biosynthesis is regulated by polysialyltransferases. It has been found that polysialic acid is also aberrantly re-expressed on the surface of many tumors, where it plays a key role in disease progression and metastasis [34]. Therefore, polysialyltransferases have been also considered as an attractive anti-cancer drug target. Fukuda's group synthesized CMP-sialic acid analogs 5-methyl CMP (58) and 2'-O-methyl CMP (59) (Table 3) as polysialyltransferase inhibitors [35]. They found that $2^{\prime}-0$-methyl CMP (59) and moderately by 5-methyl CMP (58) strongly inhibited ST8SiaIV as well as ST8Sia-II and ST8Sia-III. Moreover, 5-methyl CMP (58), 2 '-O-methyl CMP (59), and CMP (60) could reduce the polysialic acid expression on the cell surface. In addition, they found that 5-methyl CMP (58) and 2'-O-methyl CMP (59) inhibited ST3Gal-III, ST3Gal-IV and ST6Gal-I in different degrees as well. Recently, this group and their collaborators further confirmed that the pharmacological inhibition of polysialyltransferase ST8Siall modulates tumor cell migration [36]. These results indicated that analogs 5-methyl CMP (58) and 2'-0-methyl CMP (59) can be used to preferentially inhibit polysialyltransferases and their further in vivo studies for anticancer drug development are much expected.

\subsection{Oligosaccharide derivatives}

Considerable effort has also been dedicated to the design and synthesis of inhibitors of sialylation processing enzymes focusing on the receptor specificity by using modified lactose and lactosamine [37-39]. Through the studies of structure-effective relationship, Wlasichuk and co-workers reported that the C-6' hydroxyl and acetamido group of LacNAc are essential for sialylation by rat liver $\alpha 2,6$-sialyltransferase [37]. Methylation of the C-6 and C-2' hydroxyls of LacNAc had only a minimal effect on $\alpha 2,3$-sialyltransferase [39], but there was no inhibition of $\alpha 2,3$-sialyltransferase when the $\mathrm{C}-2$ ' hydroxyl of LacNAc was epimerized [38]. In addition, fluorine-containing mucin core 2 oligosaccharide analogs in which the fluorine atom located at different positions of galactose residue were synthesized in a convergent way for probing carbohydrate-enzyme interaction and carbohydrate-selectin interaction. As a result, these compounds (61-65 in Table 4) showed inhibitory activities against sialyltransferases, which indicated that the fluorine modification dramatically decreased the donor reactivity due to electron-withdrawing effect [40].

\subsection{Aromatic compounds}

Natural products are great resources for drug discovery. Polyphenol natural products possess radical scavenging and anti-oxidative properties and exhibit many biological activities, such as anti-inflammatory, antimicrobial, anti-cancer, and chemopreventive activities. In addition, they show to inhibit cell adhesion. Therefore, aromatic natural products were screened as sialyltransferase inhibitors related to anticancer and anti-inflammatory therapy. Gallic acid (66, GA), gallate esters (67) and (-)-epigallocatechin gallate (68, EGCG) were reported to inhibit $\alpha 2,3-(N)$-sialyltransferase in the low micromolar range (Table 5) [41]. In addition, Cory's group synthesized 5 negatively charged sulfonic acid analogs of natural products (69-73) (Table 5), which were tested to inhibit the sialyltransferase by the sialyltransferase assay based on transferring of ${ }^{\text {FITC }}$ NeuAc from CMP- ${ }^{\text {FITC }}$ NeuAc to $N$-linked (mediated by ST6Gal $I$ and ST3Gal III) and $O$-linked (mediated by ST3Gal I) glycans of asialo-fetuin [42]. As a result, compound 73 showed strong inhibition against $\alpha 2,3$-sialyltransferases (ST3Gal III, IC $\mathrm{IC}_{50}=3.1 \mu \mathrm{M}$; ST3Gal I, IC I0 $=14.1 \mu \mathrm{M}$ ), and $\alpha 2,6$-sialyltransferase (ST6Gal I, IC $\mathrm{I}_{50}=$ $10.8 \mu \mathrm{M}$ ), while compound 71 exhibited a more than 250 -fold $\left(\mathrm{IC}_{50}=1.7 \mu \mathrm{M}\right)$ higher potency for ST3Gal III than for all the other sialyltransferases. Future in vivo studies for anticancer drug development are much expected.

\subsection{Flavonoids}

Nature product flavonoids have various bioactivities such as antiviral and antioxidation activity and are explored as candidates for drug development. Flavonoid derivatives (74-81) were tested as sialyltransferase inhibitors on $\beta$-galactoside $\alpha 2,6$-sialyltransferase I (ST6Gal I) and $\beta$-galactoside $\alpha 2,3$-sialyltransferase $[43,44]$. Three characteristic features of flavonoids were determined by structure-inhibitory activity relationships. First, a double bond between $\mathrm{C} 2-\mathrm{C} 3$ linkages is required for the activity. Second, increasing hydrophilic properties on the B-ring markedly augmented the inhibitory effect. Third, a hydrophobic functional group introduced on the hydroxyl groups of the A-ring enhanced the inhibitory activity (Table 6). These results indicated that flavonoids could inhibit sialyltransferases and their further in vivo studies for anticancer drug development are much expected.

\subsection{Lithocholic acid analogs}

As described above, ST inhibitors with a structural mimetic of transition-state analogs, bisubstrate analogs, donor analogs, and acceptor analogs were developed designed on CMP-Neu5Ac or acceptor oligosaccharides. Although these compounds were demonstrated to effectively inhibit sialyltransferases. However, these inhibitors all may have poor permeability across cell membranes and their bioavailability may be lower and thus their clinical applications are relatively limited. So far, few ST inhibitors with a cell-permeable property have been reported $[21,28]$. Chang's group designed and synthesized 16 lithocholic acid analogs (82-100) (Table 7), which employed a steroidal moiety to improve their uptake, and demonstrated to be noncompetitive inhibitors of $\alpha 2,3$-sialyltransferase ( $\alpha 2,3-\mathrm{ST}$ ) in the presence of CMP-Neu5AC [45]. Among these compounds, Lith-O-Asp (82) suppressed cancer cell metastasis likely by inhibiting FAK/paxillin signaling and expressing anti-angiogenesis factors [46]. Further, this group found a novel sialyltransferase inhibitor AL-10 (101) from the lead compound lithocholic acid analogs with potent anti-cancer effect [47]. Compound 
Table 3

Cytidine analog inhibitors of sialyltransferases.<smiles>[R]C(=O)NS(=O)(=O)OOC1C(O)C(O)C1n1ccc(N)nc1=O</smiles>

$18 \mathrm{R}=19 \mathrm{R}=\mathrm{AcHN}_{20}^{\mathrm{OH}}=\underbrace{\mathrm{OMMe}}_{\mathrm{ONO}_{2}}$

$21 \mathrm{R}=\mathrm{N}_{\mathrm{NO}_{2}}{ }_{22 \mathrm{R}}{ }^{\mathrm{MeO}} \mathrm{i} 23 \mathrm{R}=\mathrm{I}_{\mathrm{COOM}}$

$24 \mathrm{R}=1 \mathrm{C}_{\mathrm{OH}} 25 \mathrm{R}=\mathrm{i}_{\mathrm{COONa}}^{\mathrm{OMe}} 26 \underbrace{}_{\mathrm{COOM}}$

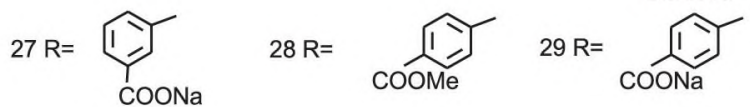

$30 \mathrm{R}={ }_{\text {COOMe }}^{\mathrm{O}_{2} \mathrm{~N}} 31 \mathrm{R}={ }_{\text {COONa }}^{\mathrm{O}_{2} \mathrm{~N}} 32 \mathrm{R}=\mathrm{ir}$

$33 \mathrm{R}=$ 舟

Inhibition of enzyme: $\alpha 2,6$-STs (Ref: [28])

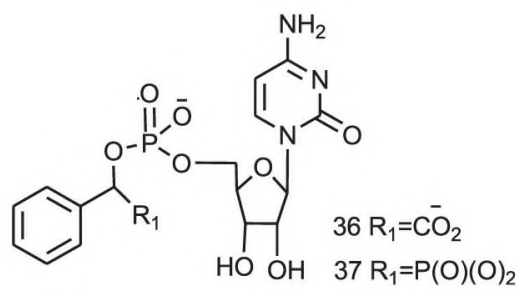

Inhibition of enzyme: $\alpha 2,6$-STs (Ref: [29])<smiles>Nc1cnc(=O)n(C2OC(COP(=O)([O-])OP(=O)([O-])[C@@H](c3nccs3)P(=O)([O-])O)C2O)c1</smiles>

43 (Ref: [30])

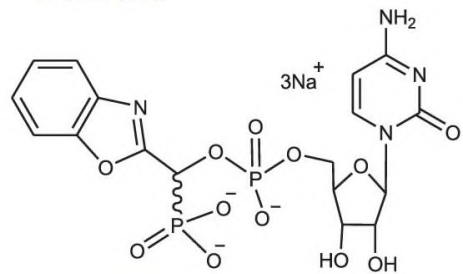

45 (Ref: [30])<smiles></smiles>

$38 \mathrm{R}_{1}=\overline{\mathrm{CO}}_{2} \quad \mathrm{R}_{2}=\mathrm{H} \quad \mathrm{R}_{3}=\mathrm{H}$

$39 \mathrm{R}_{1}=\mathrm{P}(\mathrm{O})(\overline{\mathrm{O}})_{2} \quad \mathrm{R}_{2}=\mathrm{H} \quad \mathrm{R}_{3}=\mathrm{H}$

$40 \mathrm{R}_{1}=\mathrm{CO}_{2} \quad \mathrm{R}_{2}=\mathrm{CO}_{2} \quad \mathrm{R}_{3}=\mathrm{H}$

$41 \mathrm{R}_{1}=\mathrm{P}(\mathrm{O})(\overline{\mathrm{O}})_{2} \quad \mathrm{R}_{2}=\mathrm{P}(\mathrm{O})(\mathrm{O})_{2} \quad \mathrm{R}_{3}=\mathrm{H}$

$42 \mathrm{R}_{1}=\mathrm{P}(\mathrm{O})(\overline{\mathrm{O}})_{2} \quad \mathrm{R}_{2}=\mathrm{H} \quad \mathrm{R}_{3}=\mathrm{Ph}$

Inhibition of enzyme: $\alpha 2,6-S T s$ (Ref: [29])<smiles>Nc1ccn(C2OC(COP(=O)([O-])OC(SP(=O)([O-])[O-])c3nc4ccccc4s3)C(O)C2O)c(=O)n1</smiles>

44 (Ref: [30])<smiles>Nc1ccn(C2OC(COP(=O)([O-])OC(SP(=O)([O-])[O-])c3cc4ccccc4s3)C(O)C2O)c(=O)n1</smiles>

46 (Ref: [30]) 
<smiles>Nc1ccn(C2OC(COP(=O)([O-])OC(c3cccs3)P(=O)([O-])OC(F)(F)F)C(O)C2O)c(=O)n1</smiles>

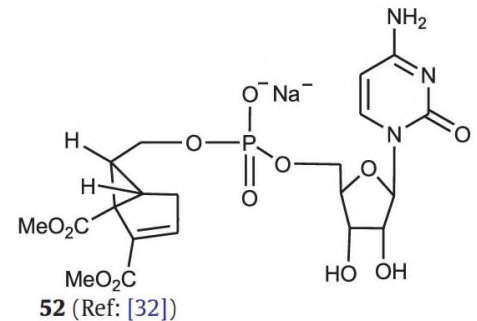<smiles>CC(=O)C1C2CCC1(COP(=O)([O-])OCC1OC(n3ccc(N)nc3=O)C1O)C2O</smiles>
54 (Ref: [32])

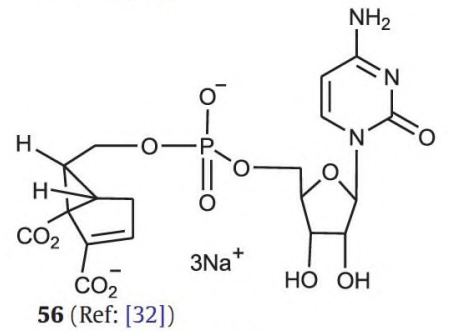<smiles>Cc1cn(C2OC(COP(=O)(O)O)C(O)C2O)c(=O)nc1N</smiles>

58

Inhibition of enzyme: ST8Sia II, ST3Gal-1ll, ST6Gal-1, ST3Gal-IV, ST8Sia-Ill, ST8Sia-IV, polyST (Refs: $[35,36]$ )<smiles>[R]c1cn(CC2OC(n3ccc(N)nc3=O)C(O)C2O)nn1</smiles>

$48 \mathrm{R}=\mathrm{CH}_{2} \mathrm{CH}_{2} \mathrm{COOH}$

$49 \mathrm{R}=\mathrm{CH}_{2} \mathrm{CH}_{2} \mathrm{OH}$

$50 \mathrm{R}=\mathrm{CH}$ (cyclopentyl) $\mathrm{OH}$

$51 \mathrm{R}=\mathrm{C}\left(\mathrm{CH}_{3}\right)$ (phenyl) $\mathrm{OH}$

Inhibition of enzyme: $\alpha 2,3-\mathrm{STs}$ (Ref: [31])

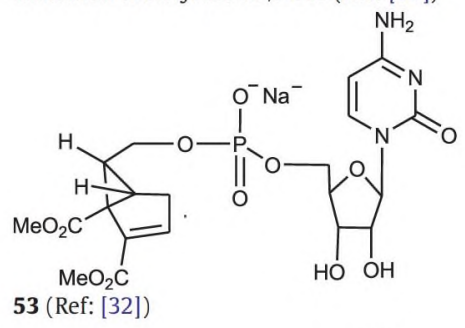

53 (Ref: [32])

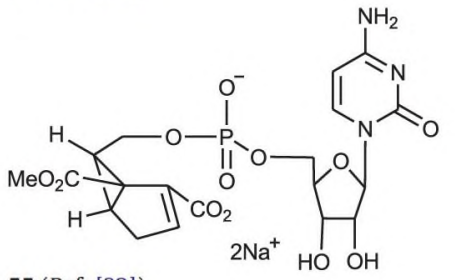

55 (Ref: [32])<smiles>Nc1ccn(C2OC3C(O)C2OP(=O)([O-])OCC2C(O)C4CC=C(C4O)C23)c(=O)n1</smiles>

57 (Ref: [32])<smiles>COC1C(O)C2OC1C2OP(=O)(O)O</smiles>

Inhibition of enzyme: ST8Sia ll, ST3Gal-III, ST6Gal-1, ST3Gal-IV, ST8Sia-lII, ST8Sia-IV, polyST (Refs: [35,36])
101 was cell-permeable and effectively attenuates total sialylation on cell surface. Interestingly, this inhibitor compound had no cytotoxicity but inhibited adhesion, migration, actin polymerization and invasion of $\alpha 2,3-$ ST-overexpressing A549 and CL1.5 human lung cells. Inhibition of adhesion and migration by compound 101 is associated with reduced sialylation of various integrin molecules. Further, compound 101 significantly suppresses experimental lung metastasis in vivo without affecting the liver and kidney function of experimental animals as determined by serum biochemical assays. Taken together, compound $\mathbf{1 0 1}$ is the first ST inhibitor, which exhibits potent anti-metastatic activity in vivo and thus is worthy for further preclinical testing as a novel drug for cancer treatment.

\subsection{Others}

Some other natural products (Table 8) were also found to act as inhibitors of sialyltransferases, such as three known spirocyclic drimanes (102-104) isolated from the culture broth of the fungus Stachybotrys cylindrospora possessed inhibitory activity sialyltransferase but not 31,4-galactosyltransferase [48]. In addition, polyoxometalates (PMs) as discrete metal-oxide cluster anions, specified by high solubility in water and highly structure-selective activity, were investigated with an interest as a candidate of inorganic drug. Akira's group reported some types of PMs, molybdate tungstate and vanadate having the ability to inhibit specific STs [49]. 
Table 4

Oligosaccharide inhibitors of sialyltransferases.

\begin{tabular}{|c|c|}
\hline Inhibition of enzyme: $\alpha 2,3-\mathrm{STs}$ (Ref: [40]) & Inhibition of enzyme: $\alpha 2,6(\mathrm{~N}) \mathrm{Sia}-\mathrm{T}, \alpha 2,3(\mathrm{~N}) \mathrm{Sia}-\mathrm{T}$ (Ref: $[40])$ \\
\hline
\end{tabular}

Table 5

Aromatic compound inhibitors of sialyltransferases.<smiles>O=C(O)c1cc(O)c(O)c(C(F)(F)F)c1</smiles>

Inhibition of enzyme: STs (Ref: [41])<smiles>O=C(OC1Cc2c(O)cc(O)cc2OC1c1cc(O)c(O)c(O)c1)c1cc(O)c(O)c(O)c1</smiles>

68

Inhibition of enzyme: STs (Ref: [41])<smiles>O=C1c2cc(S(=O)(=O)O)ccc2CCC1S(=O)(=O)O</smiles>

70

Inhibition of enzyme: ST3Gal III, ST3Gal I, ST6Gal I (Ref: [42])<smiles>O=C(O)c1ccccc1Sc1cc(C(=O)O)c(Sc2ccccc2C(=O)O)cc1C(=O)O</smiles>

Inhibition of enzyme: ST3Gal III, ST3Gal I, ST6Gal I (Ref: [42])<smiles></smiles>

67

Inhibition of enzyme: STs (Ref: [41])<smiles>O=[N+]([O-])c1ccc(/C=C/c2ccc([N+](=O)[O-])cc2S(=O)(=O)O)c(S(=O)(=O)O)c1</smiles>

69

Inhibition of enzyme: ST3Gal III, ST3Gal I, ST6Gal I (Ref: [41])
71<smiles>O=C(O)/C=C\C(=O)Nc1ccccc1SCC(O)Cn1ccc(C(F)(F)F)n1</smiles>

Inhibition of enzyme: ST3Gal III, ST3Gal I, ST6Gal I (Ref: [42])<smiles>NC1=NN(c2ccc(Oc3ccccc3)c(S(=O)(=O)O)c2)C(=O)C1</smiles>

73

Inhibition of enzyme: ST3Gal III, ST3Gal I, ST6Gal I (Ref: [42])

\section{Summary and future perspective}

Sialyltransferases as glycosyltransferases control the linkage and level of cell surface sialic acids and play key roles in many biological processes of human health and disease, such as inflammation, cancer and infection diseases. Therefore, STs are potential drug targets in a range of therapeutic areas. Over the past decades, several potent sialyltransferase inhibitors have been designed based on the enzyme donor analog or receptor analog theory and assumptions of the transition state in the active site, which exhibit inhibition constants in the low concentration range. In addition, natural products as noncompetitive sialyltransferase inhibitors were found with potent inhibitory activities. Overall, eight types of sialyltransferase inhibitors were summarized in this review, and sialic acid analogs, CMP-sialic acid analogs and cytidine analogs are the main inhibitors of sialyltransferases, which could be recognized by the enzyme. However, most nucleotide analogs have poor membrane permeability and have less chance to be developed as drug candidates. Therefore, further research such as modifying with acetyl or other group to improve the membrane permeability of nucleotide analogs may facilitate the high chance for drug development. In addition, site specific sialyltransferase inhibition should be explored in order to avoid disrupting the physiologically important sialylation and thus for therapeutic efficiency. On the other hand, natural products, such as lithocholic acid analogs, flavonoids and aromatic analogs were found as sialyltransferase inhibitors. These compounds will serve as lead compounds for sialyltransferase-targeting drug development too. The search for potent inhibitors of sialyltransferases is still challenging because rational drug design are 
<smiles>O=c1cc(-c2ccc(O)cc2)oc2cc(O)cc(O)c12</smiles>

Inhibition of enzyme: STs (Ref: [43])<smiles>[R]c1cc(-c2cc(=O)c3ccccc3o2)cc([R])c1[R]</smiles>

Inhibition of enzyme: STs (Refs: [43,44])<smiles>O=C(OC1Cc2ccccc2OC1c1cc(O)c(O)c(O)c1)c1cc(O)c(O)c(O)c1</smiles>

75

Inhibition of enzyme: STs (Ref: [44])<smiles>[R]c1cc(-c2oc3ccccc3c(=O)c2O)cc([R])c1[R]</smiles>

nhibition of enzyme: still impossible so far. This is explained at least in part by the complexity and flexibility of the macromolecule and this should be considered in structure-based inhibitor design for sialyltransferases. Nevertheless, the studies so far have unlocked the potential for inhibition of sialyltransferases as an exciting and desperately needed therapeutic opportunity for diseases such as cancer. There is no doubt that continuing basic and preclinical researches related to sialyltransferase inhibition will provide promising outcome for human health.

\section{Statement of conflict of interest}

Authors claim no conflict of interest.

Table 7

Lithocholic acid inhibitors of sialyitransferases.<smiles>CC12CCC3C(CCC4CC(OC(=O)[C@H](N)CC(=O)O)CCC43C)C1CCC2=O</smiles>

82

Inhibition of enzyme: $\alpha 2,3-S T s$ (Refs: [45,46])

$\mathrm{HO}$<smiles>CC12CCC3C(CCC4C[C@H](OC(=O)CCC(=O)O)CCC43C)C1CCC2=O</smiles>

84

Inhibition of enzyme: $\alpha 2,3-S T s$ (Ref: [45])<smiles>C[C@H](CCCOP(=O)(Oc1ccccc1)Oc1ccccc1)C1CCC2C3CCC4C[C@@H]([OH2+])CCC4(C)C3CCC21C</smiles>

Inhibition of enzyme: $\alpha 2,3-S T s$ (Ref: [45])<smiles>C[C@H](CCC(=O)NC(CC(=O)O)C(=O)O)C1CCC2C3CCC4C[C@@H](O)CCC4(C)C3CC[C@@]21C</smiles>

Inhibition of enzyme: $\alpha 2,3-S T s$ (Ref: [45])<smiles>CC12CCC(OP(=O)(O)O)CC1CC1CCC3(C)C(=O)CCC3C1CC2</smiles>

83

Inhibition of enzyme: $\alpha 2,3-S T s$ (Ref: [45])<smiles>C[C@H](CCCO)[C@H]1CCC2C3CCC4C[C@H](O)CCC4(C)C3CCC21C</smiles>

Inhibition of enzyme: $\alpha 2,3-S T s$ (Ref: [45])<smiles>C[C@@H](CCC(=O)NCC(=O)O)C1CCC2C3CCC4C[C@@H](O)CCC4(C)C3CCC21C</smiles>

Inhibition of enzyme: $\alpha 2,3-S T s$ (Ref: [45])<smiles>C[C@H](CCC(=O)O)C1CCC2C3CCC4CC(=O)CCC4(C)C3CCC21C</smiles>

Inhibition of enzyme: $\alpha 2,3-S T s$ (Ref: [45]) 
<smiles>C[C@H]1CCC2C3CCC4C[C@H](OC(=O)CNC(=O)O)CCC4(C)C3CCC21C</smiles>

Inhibition of enzyme: $\alpha 2,3-S T s$ (Ref: [45])<smiles>C[C@H](CCC(=O)OC(C)(C)C)C1CCC2C3CCC4C[C@@H](OC(=O)CCC(=O)O)CCC4(C)C3CCC21C</smiles>

Inhibition of enzyme: $\alpha 2,3-S T s$ (Ref: [45])<smiles>C[C@H](CCC(=O)NC(CC(=O)O)C(=O)O)C1CCC2C3CCC4C[C@@H](OC(=O)CCC(=O)O)CCC4(C)C3CCC21C</smiles>

Inhibition of enzyme: $\alpha 2,3-S T s$ (Ref: [45])<smiles>C[C@H](CCCn1cc(CCO)nn1)C1CCC2C3CCC4C[C@@H]([SH2+])CCC4(C)C3CCC21C</smiles>

Inhibition of enzyme: $\alpha 2,3-$ STs (Ref: [45])<smiles>COP(=O)(OC)[C@H](Cc1cn(CCC[C@H](C)C2CCC3C4CCC5C[C@@H](O)CCC5(C)C4CCC32C)nn1)C(=O)O</smiles>

98

Inhibition of enzyme: $\alpha 2,3-S T s$ (Ref: [45])<smiles>C[C@H](CCCn1cc(CCCC(=O)O)nn1)C1CCC2C3CCC4C[C@@H](O)CCC4(C)C3CCC21C</smiles>

100

Inhibition of enzyme: $\alpha 2,3-S T s$ (Ref: [46])

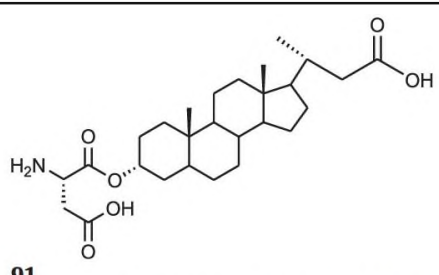

91

Inhibition of enzyme: $\alpha 2,3-$ STs (Ref: [45])<smiles>CCCCCCCCCCC(=O)NC(=O)O</smiles>

Inhibition of enzyme: $\alpha 2,3-S T s$ (Ref: [45])<smiles>C[C@H](CCC(=O)O)C1CCC2C3CCC4C[C@H](CC(=O)C(N)CC(=O)O)CCC4(C)C3CCC21C</smiles>

95

Inhibition of enzyme: $\alpha 2,3-S T s$ (Ref: [45])<smiles>C[C@H](CCCn1cc(C[C@H](N)C(=O)O)nn1)C1CCC2C3CCC4C[C@@H](O)CCC4(C)C3CCC21C</smiles>

97

Inhibition of enzyme: $\alpha 2,3-$ STs (Ref: [45])<smiles>C[C@H](CCCn1cc(CCC(=O)O)nn1)C1CCC2C3CCC4C[C@@H](O)CCC4(C)C3CCC21C</smiles>

99

Inhibition of enzyme: $\alpha 2,3-S T s$ (Ref: [45])<smiles>C[C@H](CCC(=O)O)C1CCC2C3CCC4C[C@H](CC(=O)[C@H](CCC(=O)O)Nc5ccc([N+](=O)[O-])c6nonc56)CCC4(C)C3CCC21C</smiles>

101

Inhibition of enzyme: $\alpha 2,3-$ STs (Ref: [47])
Table 8

Spirocyclic drimane inhibitors of sialyltransferases.

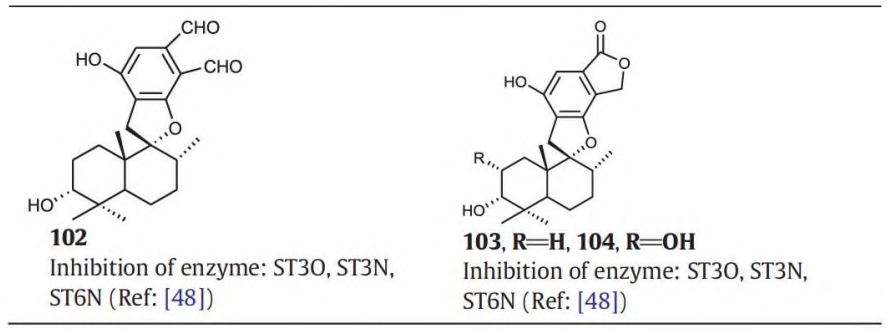

\section{Acknowledgment}

This work was supported by the American Heart Association Grant-in Aid (14GRANT20290002) and Research fund from the Center for Gene Regulation in Health and Disease (GRHD) at Cleveland State University (GRHD08) supported by Ohio Department of Development (ODOD). L. Wang appreciates the China Oversea Scholar Award from China Scholarship Council.

\section{References}

[1] X. Chen, A. Varki, Advances in the biology and chemistry of sialic acids, ACS Chem. Biol. 5 (2010) 163-176.

[2] R. Schauer, Sialic acids as regulators of molecular and cellular interactions, Curr. Opin. Struct. Biol. 19 (2009) 507-514.

[3] A. Varki, P. Gagneux, Multifarious roles of sialic acids in immunity, Ann. N. Y. Acad. Sci. 1253 (2012) 16-36. 
14] A. Varki, Sialic acid in human health and disease, Trends Mol. Med. 14 (2008) 351-360.

[5] H.J. Crespo, J.T. Lau, P.A Videira, Dendritic cells: a spot on sialic acid, Front Immunol. 4 (2013) 491.

[6] A. Harduin-Lepers, V. Vallejo-Ruiz, M.A. Krzewinski-Recchi, B. Samyn-Petit, S. Julien, P. Delannoy, The human sialyltransferase family, Biochimie 83 (2001) 727-737.

[7] Y. Li, X. Chen, Sialic acid metabolism and sialyltransferases: natural functions and applications, Appl. Microbiol. Biotechnol. 94 (2012) 887-905.

[8] M.B. Jones, M. Nasirikenari, L. Feng, M.T. Migliore, K.S. Choi, L Kazim, Role for hepatic and circulatory ST6Gal-1 sialyltransferase in regulating myelopoiesis, J. Biol. Chem. 285 (2010) 25009-25017.

[9] M.G. CabraI, A.R. Piteira, Z. Silva, D. Ligeiro, R. Brossmer, P.A. Videira, Human dendritic cells contain cell surface sialyltransferase activity, Immunol. Lett. 131 (2010) 89-96.

[10] A.F. Swindall, S.L. Bellis, Sialylation of the Fas death receptor by ST6Gal-l provides protection against Fas-mediated apoptosis in colon carcinoma cells, ]. Biol. Chem. 286 (2011) 22982-22990.

[11] H. Cui, Y. Lin, L. Yue, X. Zhao, J. Liu, Differential expression of the alpha2,3-sialic acid residues in breast cancer is associated with metastatic potential, Oncol. Rep. 25 (2011) 1365-1371.

[12] M. Lee, H.]. Lee, S. Bae, Y.S. Lee, Protein sialylation by sialyltransferase involves radiation resistance, Mol. Cancer Res. 6 (2008) 1316-1325.

[13] J.J. Park, J.Y. Yi, Y.B. Jin, Y.J. Lee, J.S. Lee, Y.S. Lee, Sialylation of epidermal growth factor receptor regulates receptor activity and chemosensitivity to gefitinib in colon cancer cells, Biochem. Pharmacol. 83 (2012) 849-857.

[14] K. Sakuma, M. Aoki, R. Kannagi, Transcription factors c-Myc and CDX2 mediate E-selectin ligand expression in colon cancer cells undergoing EGF/bFGF-induced epithelial-mesenchymal transition, Proc. Natl. Acad. Sci. U. S. A. 109 (2012) 7776-7781.

[15] K.A. Maupin, A. Sinha, E. Eugster, J. Miller, J. Ross, V. Paulino, Glycogene expression alterations associated with pancreatic cancer epithelial-mesenchymal transition in complementary model systems, PLOS ONE 5 (2010) e13002.

[16] M. Dalziel, F. Dall'Olio, A. Mungul, V. Piller, F. Piller, Ras oncogene induces beta galactoside $\alpha 2,6$-sialyltransferase (ST6Gal 1) via a RalGEF mediated signal to its housekeeping promoter, Eur. J. Biochem. 271 (2004) 3623-3634.

[17] X. Wang, L.H. Zhang, X.S. Ye, Recent development in the design of sialyltransferase inhibitors, Med. Res. Rev. 23 (2003) 32-47.

[18] K.-H. Jung, R. Schworer, R.R. Schmidt, Sialyltransferase inhibitors, Trends Glycosci. Glycotechnol. 15 (2003) 275-289.

[19] L.L. Lairson, B. Henrissat, G.]. Davies, S.G. Withers, Glycosyltransferases: structures, functions, and mechanisms, Annu Rev. Biochem. 77 (2008) 521-555.

[20] M.D. Burkart, S.P. Vincent, A. Duffels, B.W. Murray, S.V. Ley, C.H. Wong, Chemo-enzymatic synthesis of fluorinated sugar nucleotide: useful mechanistic probes for glycosyltransferases, Bioorg. Med. Chem. 8 (2000) 1937-1946.

[21] C.D. Rillahan, A Antonopoulos, C.T. Lefort, R. Sonon, P. Azadi, K. Ley, A. Dell, S.M. Haslam, J.C. Paulson, Global metabolic inhibitors of sialyl- and fucosyltransferases remodel the glycome, Nat. Chem. Biol. 8 (2012) 661-668.

[22] M.S. Macauley, B.M. Arlian, C.D. Rillahan, P.C. Pang, N. Bortell, M.C.G. Marcondes, S.M. Haslam, A. Dell, J.C. Paulson, Systemic blockade of sialylation in mice with a global inhibitor of sialyltransferases, J. Biol. Chem. 289 (2014) $35149-35158$

[23] C. Buell, T.]. Boltje, M. Wassink, M.A. Annemarie, F.L. van Delft, M.H. den Brok, G.J Adema, Targeting aberrant sialylation in cancer cells using a fluorinated sialic acid analog impairs adhesion, migration, and in vivo tumor growth, Mol. Cancer Ther. 12 (2013) 1935-1946.

[24] C. Bull, T.J. Boltje, E.A. van Dinther, T. Peters, A.M. de Graaf, ].H. Leusen, M. Kreutz, C.G. Figdor, M.H. den Brok, G.J. Adema, Targeted delivery of a sialic acid-blocking glycomimetic to cancer cells inhibits metastatic spread, ACS Nano 9 (2015) $733-745$.

[25] I. Masayuki, W. Katsuhiro, Y. Hideya, H. Hironobu, Synthesis of bisubstrate and donor analogues of sialyltransferase and their inhibitory activities, J. Org. Chem 70 (2005) 8817-8824.

[26] K. Hosoguchi, T. Maeda, J. Furukawa, Y. Shinohara, H. Hinou, M. Sekiguchi, H. Togame, H. Takemoto, H. Kondo, S.l. Nishimura, An efficient approach to the discovery of potent inhibitors against glycosyltransferases, J. Med. Chem. 53 (2010) 5607-5619.
[27] K. Suzuki, A. Ohtake, I. Yukishige, O. Kanie, Synthesis of a fluorescently tagged sialic acid analogue useful for live-cell imaging, Chem. Commun. 48 (2012) 9744-9746.

[28] R. Kumar, R. Nasi, M. Bhasin, N.H. Khieu, M. Hsieh, M. Gilbert, H. Jarrell, W. Zou, H.]. Jennings, Sialyltransferase inhibitors: consideration of molecular shape and charge/ hydrophobic interactions, Carbohydr. Res. 378 (2013) 45-55.

[29] S. Danielle, S. Ralf, H. Tobias, R.R. Schmidt, Asymmetric synthesis and affinity of potent sjaly]transferase inhibitors based on transition-state analogs, Glycoconjugate J. 21 (2004) 205-219.

[30] M. Bini, R.R. Schmidt, Potentia] sialyltransferase inhibitors based on neuraminyl substitution by heteroaryl rings, Carbohydr. Res. 342 (2007) 558-566.

[31] L Lee, K.H. Chang, F. Valiyev, H.]. Liu, W.S. Li, Synthesis and biological evaluation of 5'-triazole nucleosides, J. Chin. Chem. Soc. 53 (2006) 1547-1555.

[32] N. Satomi, K.V. Subbarao, H. Wang, X. Chen, Synthetic studies of new CMP-sialic acid analogs applying a novel buffer-mediated rearrangement, Tetrahedron Lett. 48 (2007) 8757-8760.

[33] K. Angata, M. Fukuda, Carbohydrates of neural cell glycoproteins: structure, biosynthesis and function, in: M. Fukuda, U. Rutishauser, R.L. Schnaar (Eds.), Neuroglycobioloy, Oxford University Press, Oxford 2005, pp. 1-38.

[34] R.A. Falconer, R.]. Errington, S.D. Shnyder, P.J. Smith, LH. Patterson, Polysialyltransferase: a new target in metastatic cancer, Curr. Cancer Drug Targets 12 (2012) 925-939.

[35] T. Miyazaki, K. Angata, P.H. Seeberger, O. Hindsgaul, M. Fukuda, CMP substitutions preferentially inhibit polysialic acid synthesis, Glycobiology 18 (2008) 187-194.

[36] Y.M.J. Al-Saraireh, M. Sutherland, B.R. Springett, F. Freiberger, G.R. Morais, P.M. Loadman, R.J. Errington, P.J. Smith, M. Fukuda, R.G. Schahn, L.H. Patterson, S.D. Shnyder, RA. Faiconer, Pharmacological inhibition of polysialyltransferase ST8SialI modulates tumor cell migration, PLoS ONE 8 (2013) e73366.

[37] K.B. Wlasichuk, M. Kashem, P.V. Nikrad, P. Bird, C. Jiang, A.P. Venot, Determination of the specificities of rat liver Gal $(\alpha)-4)$ GicNAc $\alpha 2,6$-sialyltransferase and Gal $(\alpha 1-3 /$ 4) GlcNAC $\alpha 2,3$-sialyltransferase using synthetic modified acceptors, J. Biol. Chem. 268 (1993) 13971-13977.

[38] F.M. Perron-Sierra, M. Burbridge, C. Pean, G.C. Tucker, P. Casara, Synthesis of a nove] dioxan sialic acid analog. Tetrahedron lett. 45 (2004) 4163-4166.

[39] M.C. Galan, A.P. Venot, G.]. Boons, Glycosyltransferase activity can be modulated by small conformational changes of acceptor substrates, Biochemistry 42 (2003) $8522-8529$.

[40] J. Xia, J. Xue, R.D. Locke, E.V. Chandrasekaran, T. Srikrishnan, K.L. Matta, Synthesis of fluorinated mucin core branched oligosaccharides with the potential of novel substrates and enzyme inhibitors for glycosyltransferases and sulfotransferases, ]. Org. Chem. 71 (2006) 3696-3706.

[41] X. Niu, X. Fan, J. Sun, P. Ting, S. Narula, D. Lundell, Inhibition of fucosyltransferase Vl] by gallic acid and its derivatives, Arch. Biochem. Biophys. 425 (2004) 51-57.

[42] C.D. Rillahan, S.J. Brown, A.C. Register, H. Rosen, J.C. Paulson, High-throughput screening for inhibitors of sialyl- and fucosyltransferases, Angew. Chem. Int. Ed. 50 (2011) 12534-12537.

[43] K.I.P.J. Hidari, K. Oyama, G. Ito, M. Nakayama, M. Inai, S. Goto, Y. Kanai, K. Watanabe, K. Yoshida, T. Furuta, Identification and characterization of flavonoids as sialyltransferase inhibitors, Biochem. Biophys. Res. Commun. 382 (2009) 609-613.

[44] T. Kan, Synthesis and bioactivity evaluation of catechin and flavonoid, Pacifichem, International Chemical Congress of Pacific Basin Societies, Honolulu, HI, United StatesDecember 2010. 15-20.

[45] K.H. Chang, L. Lee, J. Chen, W. Li, Lithocholic acid analogues, new and potent $\alpha-2,3-$ sialyltransferase inhibitors, Chem. Commun. 6 (2006) 629-631.

[46] J. Chen, Y. Tang, S. Huang, H. Juan, L. Wu, Y. Sun, S. Wang, K. Wu, G. Balraj, T. Chang, A novel sialyltransferase inhibitor suppresses FAK/paxillin signaling and cancer angiogenesis and metastasis pathways, Cancer Res. 71 (2011) 473-483.

[47] C.H. Chiang, C.H. Wang, H.C. Chang, V. More Shivaji, W.S. Li, W. Hung, A novel sialyltransferase inhibitor AL10 suppresses invasion and metastasis of lung cancer cells by inhibiting integrin-mediated signaling. J. Cell Physiol. 223 (2010) 492-499.

[48] T.W. Lin, W.W. Chang C.C. Chen, Y.C. Tsai, Stachybotrydial, a potent inhibitor of fucosyltransferase and sialyltransferase, Biochem. Biophys. Res. Commun. 331 (2005) 953-957

[49] A. Seko, T. Yamase, K. Yamashita, Polyoxometalates as effective inhibitors for sialyland sulfotransferases, J. Inorg. Biochem. 103 (2009) 1061-1066. 